\title{
Stationary Phase
}

National Cancer Institute

\section{Source}

National Cancer Institute. Stationary Phase. NCI Thesaurus. Code C70673.

The non-moving substance contained in a chromatography column that causes separation. 